Article

\title{
Efficiently Anti-Obesity Effects of Unsaturated Alginate Oligosaccharides (UAOS) in High-Fat Diet (HFD)-Fed Mice
}

\author{
Shangyong $\mathrm{Li}^{1,{ }^{\dagger}}$, Ningning $\mathrm{He}^{1, *,+}$ and Linna Wang ${ }^{2, *}$ \\ 1 Department of Pharmacology, College of basic Medicine, Qingdao University, Qingdao 266071, China; \\ 1shywln@163.com \\ 2 Yellow Sea Fisheries Research Institute, Chinese Academy of Fishery Sciences, Key Laboratory for \\ Sustainable Development of Marine Fisheries, Ministry of Agriculture, Qingdao 266071, China \\ * Correspondence: heningning@qdu.edu.cn (N.H.); wangln@ysfri.ac.cn (L.W.); Tel.: +86-532-8381-6785 (N.H.); \\ +86-532-8378-0013 (L.W.) \\ + These authors contributed equally.
}

Received: 21 August 2019; Accepted: 12 September 2019; Published: 17 September 2019

\begin{abstract}
Obesity and its related complications have become one of the leading problems affecting human health. However, current anti-obesity treatments are limited by high cost and numerous adverse effects. In this study, we investigated the use of a non-toxic green food additive, known as unsaturated alginate oligosaccharides (UAOS) from the enzymatic degradation of Laminaria japonicais, which showed effective anti-obesity effects in a high-fat diet (HFD) mouse model. Compared with acid hydrolyzed saturated alginate oligosaccharides (SAOS), UAOS significantly reduced body weight, serum lipid, including triacylglycerol (TG), total cholesterol (TC) and free fatty acids (FFA), liver weight, liver TG and TC, serum alanine aminotransferase (ALT), and aspartate aminotransferase (AST) levels, adipose mass, reactive oxygen species (ROS) formation, and accumulation induced in HFD mice. Moreover, the structural differences in $\beta$-D-mannuronate $(M)$ and its $C 5$ epimer $\alpha$-L-guluronate $(G)$ did not cause significant functional differences. Meanwhile, UAOS significantly increased both AMP-activated protein kinase $\alpha(\mathrm{AMPK} \alpha)$ and acetyl-CoA carboxylase (ACC) phosphorylation in adipocytes, which indicated that UAOS had an anti-obesity effect mainly through AMPK signaling. Our results indicate that UAOS has the potential for further development as an adjuvant treatment for many metabolic diseases such as fatty liver, hypertriglyceridemia, and possibly diabetes.
\end{abstract}

Keywords: unsaturated alginate oligosaccharides; hepatoprotective effect; anti-oxidant activity; anti-obesity activity

\section{Introduction}

Obesity is a genetic and health problem, as well as a social problem that seriously threatens human health. According to data from the World Health Organization (WHO) in 2016, 25\% of adults worldwide were overweight $[1,2]$. Overweight and obesity can cause complications such as type 2 diabetes, high blood pressure, cancer, and non-alcoholic fatty liver disease (NAFLD) [3,4]. However, there are limited anti-obesity drugs on the market due to their unexpected side effects, such as increasing the risk of heart attacks and psychiatric side effects [5,6]. Currently, orlistat is the only over-the-counter drug approved by the Food and Drug Administration (FDA) to help with obesity. However, it also causes a series of adverse reactions in certain people, including gastrointestinal trauma and greasy stools [7]. Therefore, it is necessary to develop alternative anti-obesity agents, including safe and effective functional foods for adjuvant therapy. 
Brown seaweed, especially Laminaria japonica (LJ), is one of the most commonly eaten seaweeds in the world, especially in Scandinavia and East Asia [8]. As a functional food, LJ and its extracts have been shown to have anti-diabetic, anti-inflammatory, anti-oxidant, and anti-cancer effects in several studies $[9,10]$. Alginate is the most abundant carbohydrate in brown algae and approximately 30,000 tons of alginate is produced annually worldwide [11,12]. Due to its good safety profile and effectiveness, alginate has been widely used in the the food and pharmaceutical industries. In nature, alginate is a linear hetero-polyuronic acid polymer, composed of $\beta$-D-mannuronate $(\mathrm{M})$ and its $\mathrm{C5}$ epimer $\alpha$-L-guluronate (G) $[12,13]$. Recently, alginate oligosaccharides (AOS) have gained greater attention due to their important biological functions, such as their ability to improve the growth of bifidobacteria, and improve cytokine-inducing activity in mononuclear cells, antioxidant activity, and plant root growth-promoting activity [14-18]. Currently, there are two different degradation protocols to produce alginate. The traditional acid hydrolysis method yields saturated alginate oligosaccharides (SAOS) as the main products, while enzymatic hydrolysis using alginate lyase produces unsaturated alginate oligosaccharides (UAOS) as the reaction products [19].

Compared with SAOS, the non-reducing ends of UAOS provide double bonds between C4 and C5, which gives them greater anti-oxidant activity than ascorbic acid in the lipid oxidation treatment [19]. Obesity-induced accumulation of liver lipids and reactive oxygen species (ROS) is a key factor in the prevalence of metabolic and cardiovascular diseases [20]. Excessive liver ROS production and decreased cellular antioxidant activity lead to oxidative stress and liver oxidative damage [21]. Therefore, antioxidants can effectively improve lipid and ROS metabolism, which reduces liver steatosis and oxidative damage. However, the in vivo antioxidant, with hepatoprotective and anti-obesity activities of UAOS, have not yet been reported. Obesity is a disorder that is related to energy imbalance. AMP-activated protein kinase (AMPK) is a crucial cellular energy sensor. Once AMPK is activated, it triggers catalytic processes to generate ATP while inhibiting anabolic processes that consume ATP in an attempt to restore cellular energy homeostasis. AMPK is considered a potential target for treating metabolic disorders [22]. It has previously been reported that anti-obesity agents activated the AMPK signaling pathway, which is related to the suppression of adipogenic differentiation and lipogenesis AMPK, such as Rg1 [23], dioxinodehydroeckol [24], and ethanol extracts of Aster yomena [25]. Increasing evidence has demonstrated that AMPK can inhibit adipogenesis and suppress the expression of SREBP-1c, PPAR $\gamma$, and FAS in adipocytes [26,27]. Therefore, in this study, we will study whether AMPK is involved in the anti-obesity mechanism of UAOS.

In this study, we investigated that UAOS showed effective anti-obesity effects, which significantly reduced body weight, serum lipid, including triacylglycerol (TG), total cholesterol (TC), and free fatty acids (FFA), liver weight, liver TG, and TC, serum alanine aminotransferase (ALT) and aspartate aminotransferase (AST) levels, adipose mass, reactive oxygen species (ROS) formation, and accumulation induced in HFD mice. This study also showed that UAOS played an anti-obesity effect mainly through an AMP-activated protein kinase $\alpha$ (AMPK $\alpha$ ) signaling pathway. UAOS may be a promising candidate for the treatment of metabolic diseases such as fatty liver, hypertriglyceridemia, and possibly type 2 diabetes.

\section{Materials and Methods}

\subsection{Materials and Supplies}

High viscosity sodium alginate (20-50 kDa, 100-260 polymerized monosaccharides, M/G ratio: 1.66) was prepared. Standard alginate disaccharide and trisaccharide were purchased from Qingdao BZ Oligo Biotech Co., Ltd (Qingdao, China). Chitosan, with a $\geq 95 \%$ degree of deacetylation (DDA), were purchased from Aladdin, China. Antibodies against p-AMPK $\alpha$ (Thr172), AMPK $\alpha$, p-ACC (Ser79), ACC, and GAPDH were purchased from Cell Signaling Technology (Beverly, MA, USA). Orlistat was purchased from Aladdin (Aladdin, Shanghai, China). A standard diet (STD) feed and a high-fat diet (HFD) feed were purchased from the Darenfucheng Animal Husbandry Company (Qingdao, China). 
The nutritional composition of a standard diet (STD) and a high-fat diet (HFD) were shown in Table S1. All chemical reagents used in this study were of an analytical grade.

\subsection{Preparation and Determination of Oligosaccharides}

Polyguluronate block (Poly G) and polymannuronate (Poly M) (DP = 20-24) were prepared from sodium alginate, according to the method of Haug et al. [28]. Two types of enzymatic unsaturated alginate oligosaccharides (UAOS) (unsaturated mannuronate oligosaccharides (UMOS) and unsaturated guluronate oligosaccharides (UGOS)) were prepared by using an alginate lyase purified in our laboratory [29]. The reaction mixture contained $\sim 20,000 \mathrm{U}$ (50 mL) of bifunctional alginate lyase Aly08 and $1 \mathrm{~L}$ of PolyM blocks or polyG blocks $(10 \mathrm{mg} / \mathrm{mL})$ in $50 \mathrm{mM}$ phosphate buffer ( $\mathrm{pH}$ 7.6). The reaction mixture was then incubated at $40{ }^{\circ} \mathrm{C}$ for $24 \mathrm{~h}$. The reaction products were analyzed by thin-layer chromatography (TLC) with the unfolding agent (butanol/acetic-acid/water $2: 1: 1, v / v)$ and the saccharides were visualized with a developing reagent (sulfuric acid/ethanol reagent $1: 4, v / v$ ) after heating the TLC plate at $80^{\circ} \mathrm{C}$ for $30 \mathrm{~min}$ [30]. The products were also analyzed by fast protein liquid chromatography (FPLC) with a Superdex peptide 10/300 gel filtration column (GE Health, Chicago, IL, USA), as previously described [31]. The Dionex software Chromeleon v7.2 (Thermo Scientific, Pittsburgh, PA, USA) was used to identify and quantify sugars. The reaction products were further characterized by negative-ion electrospray ionization mass spectrometry (ESI-MS) [19]. As a control, two types of the acid hydrolyzed saturated alginate oligosaccharides (SAOS) (saturated mannuronate oligosaccharides (SMOS) and saturated guluronate oligosaccharides (SGOS)) were prepared according to the method of Li et al., 2016 [30]. The acid hydrolysis products were also analyzed by TLC. The average molecular weight of these AOS were analyzed by the carbazole sulfate method [19]. Chitooligosaccharides (COS) are the degradation products of chitosanase CsnM [32]. The COS used in this study were also analyzed by TLC and positive-ion ESI-MS (Figure S1). The average molecular weight of COS was 714.06.

\subsection{Animals and Diet}

KM mice were provided by the Darenfucheng Animal Husbandry Company (Qingdao, China). The mice were housed in a specific-pathogen-free (SPF) room (temperature: $21 \pm 2{ }^{\circ} \mathrm{C}$, humidity: $45-65 \%$, and $12 \mathrm{~h}$ dark-light cycles). Water was given to the mice freely during experiments. After seven days of acclimation (17-18 g), mice were divided into the following ten groups (8 per group): (1) STD: standard treatment diet group, fed a normal diet for 8 weeks, (2) HFD: fed an HFD for 8 weeks, (3) COS: fed an HFD for 4 weeks and then fed an HFD with $350 \mathrm{mg} / \mathrm{kg}$ per day and COS for 4 weeks, (4) Orlistat: fed an HFD for 4 weeks and then fed a HFD with $75 \mathrm{mg} / \mathrm{kg}$ per day with Orlistat for 4 weeks, (5-7) UAOS: fed an HFD for 4 weeks and then fed an HFD with $100 \mathrm{mg} / \mathrm{kg}$ per day (L), $200 \mathrm{mg} / \mathrm{kg}$ per day (M) or $400 \mathrm{mg} / \mathrm{kg}$ per day (H) UAOM for 4 weeks, (8-10) SAOS: fed an HFD for 4 weeks and then fed an HFD with $100 \mathrm{mg} / \mathrm{kg}$ per day (L), $200 \mathrm{mg} / \mathrm{kg}$ per day (M) or $400 \mathrm{mg} / \mathrm{kg}$ per day (H) SAOS for 4 weeks. Orlistat, COS, UAOS, and SAOS were dissolved in distilled water at a concentration of $600 \mathrm{mg} / \mathrm{mL}$ and were then administered at a dose of $1 \mathrm{~mL} / 100 \mathrm{mg}$ daily by gavage. Afterwards, other $\mathrm{KM}$ mice (16-18 g) were purchased and housed as above. After 7 days of acclimation, mice were divided into the following seven groups (12 per group): (1) STD: standard treatment diet group, with 8 weeks of a normal diet, (2) HFD: with 8 weeks of HFD, (3) COS: 4 weeks of HFD and 4 weeks of HFD with $350 \mathrm{mg} / \mathrm{kg}$.day COS, (4) UMOS: 4 weeks of HFD and 4 weeks of HFD with $350 \mathrm{mg} / \mathrm{kg}$ per day UMOS, (5) UGOM: 4 weeks of HFD and 4 weeks of HFD with $350 \mathrm{mg} / \mathrm{kg}$ per day UGOM, (6) SMOS: 4 weeks of HFD and 4 weeks of HFD with $350 \mathrm{mg} / \mathrm{kg}$ per day SMOS, (7) SGOS: 4 weeks of HFD and 4 weeks of HFD with $350 \mathrm{mg} / \mathrm{kg}$ per day SGOS. COS, UMOS, UGOM, SMOS, and SGOS were dissolved in distilled water at a concentration of $600 \mathrm{mg} / \mathrm{ml}$ and were then administered at a dose of $1 \mathrm{~mL} / 100 \mathrm{mg}$ daily by gavage.

In the end of the experiment, the mice were fasted for $12 \mathrm{~h}$ and sacrificed. Blood was obtained from the retro-orbital plexus. Serum was obtained via centrifuge ( $3500 \mathrm{rpm}, 4{ }^{\circ} \mathrm{C}, 30 \mathrm{~min}$ ). Liver and 
adipose tissues were quickly stripped and weighed. After a picture was taken, the tissues were stored at $-80^{\circ} \mathrm{C}$ for further analysis. The animals used in these experiments were approved by the Ethics Committee of the Medical College of Qingdao University.

\subsection{Calculation of Energy Intake, Weight Gain, and Lee's Index}

Daily food intake was recorded and body weight and body length of each mouse were measured weekly. Lee's index was calculated from the formula: body weight $(\mathrm{g}) 1 / 3 \times 1000 /$ body length $(\mathrm{cm})$.

\subsection{Biochemical Analysis}

The concentration of triacylglycerol (TG), total cholesterol (TC), high-density lipoprotein (HDL), and low-density lipoprotein (LDL) in mouse serum was measured using commercial detection kits (Nanjing jiancheng Bioengineering Institute, Nanjing, China). An enzyme-linked immunosorbent assay kit to measure the concentration of free fatty acids (FFA) was purchased from Bio-Techne (Shanghai, China). Hepatic hydrogen peroxide concentration was measured by a hydrogen peroxide testing kit (Beyotime Biotech., Haimen, China). Hepatic lipoperoxide levels were measured using an MDA testing kit (Nanjing Jiancheng Biotec, Nanjing, China).

\subsection{Measurement of Hepatic Lipids, AST, and ALT}

Liver tissue $(0.1 \mathrm{~g})$ was homogenized with $0.9 \mathrm{~mL}$ sodium chloride $(0.9 \%)$. The supernatant was then collected via centrifugation $\left(2500 \mathrm{rpm}, 4^{\circ} \mathrm{C}, 10 \mathrm{~min}\right)$. The levels of hepatic TC, TG, AST, and ALT were determined using commercial detection kits (Nanjing jiancheng Bioengineering Institute, Nanjing, China). Hydrogen peroxide generation was assessed as previously described [33], while lipid peroxidation was quantified as malondialdehyde (MDA) and expressed as nanomoles of MDA per milligram of protein [34].

\subsection{Histological Analysis}

Tissues were dissected and washed with saline and then fixed using $10 \%$ formalin solution for $24 \mathrm{~h}$. Tissue cutting and hematoxylin and eosin (H\&E) staining were performed by Sevicebio (Wuhan, China). Images were obtained using a microscope at $200 \times$ magnification. The adipocyte sizes were determined using ImageJ (NIH, Bethesda, MD, USA) (https://imagej.nih.gov/ij/).

\section{8. mRNA Quantification by Quantitative Real-Time PCR ( $q P C R$ )}

Total RNA was isolated from tissues and qPCR were performed as previously described [35]. The primers used in this study were synthesized by Sangong Biotech (Shanghai, China) (Table S2). Gene expression levels were normalized to GAPDH and the relative quantification of gene expression was calculated using the $2^{-\Delta \Delta C t}$ method.

\subsection{Western Blotting}

Total protein content was obtained from tissue lysis using cold RIPA lysis buffer, which was followed by centrifugation at $12,000 \mathrm{~g}$ for $30 \mathrm{~min}$ at $4{ }^{\circ} \mathrm{C}$. This process was repeated three times. The BCA protein assay kit was used to quantify the harvested protein. Western blotting was performed as previously described [35].

\subsection{Statistical Analysis}

All images in this study were formatted for optimal presentation using Adobe Illustrator CS4 (Adobe Systems, Inc., San Jose, CA, USA). To determine the statistical significance between two groups, a Student's t-test was performed to calculate the associated P-values. The statistical significance between multiple groups was calculated by one-way analysis of variance (ANOVA) using the GraphPad Prism 5 (GraphPad Software, La Jolla, CA, USA). 


\section{Results}

\subsection{Separation and Determination of AOS}

Two types of AOS were prepared in this study, including enzymatic UAOS and acid hydrolyzed SAOS. UAOS was performed using a green production method developed in our previous study, by combining enzymatic hydrolysis and selective fermentation directly from LJ [19]. The scheme of UAOS and SAOS was shown in Figure 1A. The structural difference between them is that UAOS contains an unsaturated double bond between $\mathrm{C} 4$ and C5. Alginate is a linear polysaccharide containing M block and its C5 epimer G block. To further identify any differences in activity between M and G fragments, UAOS were separated into UMOS and UGOS. Meanwhile, SAOS were also separated into SMOS and SGOS as a control. According to the carbazole sulfate analysis, the average molecular weights of these four AOS were similar (UMOS, 446.5, UGOS, 441.6, SMOS, 459.6, SGOS, 455.2). To further analyze the consistency of these AOS, TLC analysis was performed. The mobility of the separated UMOS, UGOS, SMOS, and SGOS were similar (Figure 1B).

(A)

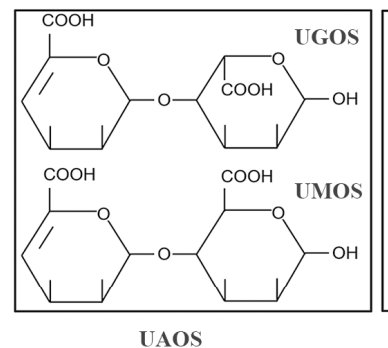

(C)

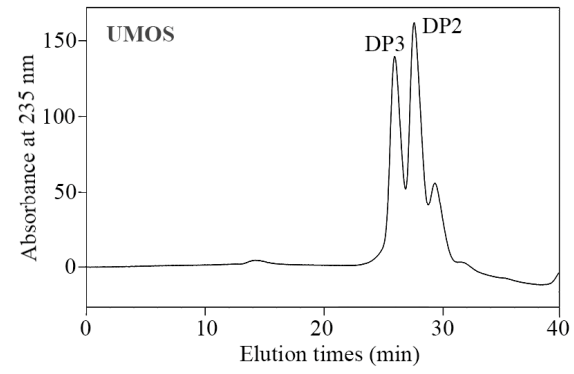

(E)

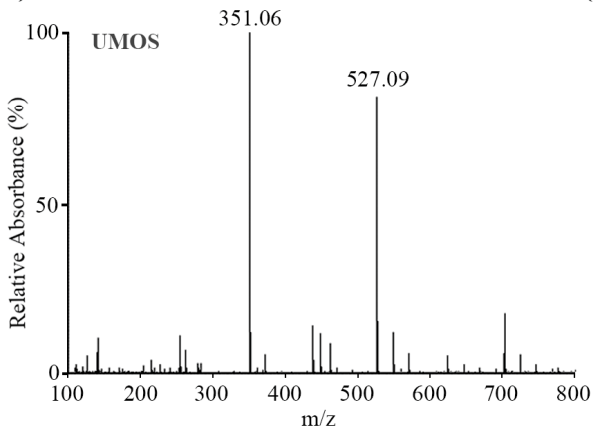

(B)

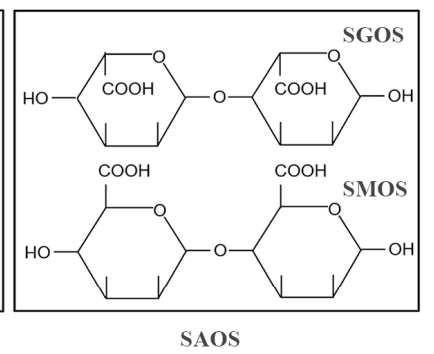

(D)

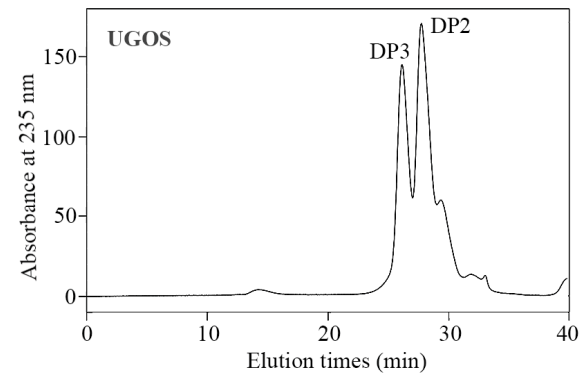

(F)

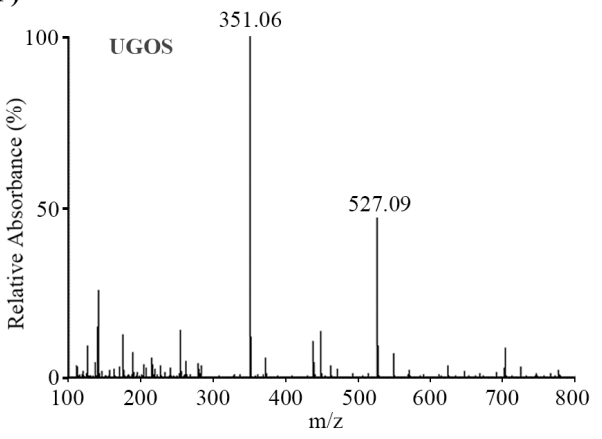

Figure 1. Scheme (A), TLC analysis (B), SE-HPLC analysis (C,D), and ESI-MS analysis (E,F) of UAOS and SAOS.

In order to analysis the main ingredient of the separated UAOS, UMOS and UGOS were measured by SE-HPLC using the Superdex peptide $10 / 300^{\mathrm{TM}}$ column. As shown in Figure $1 C, \mathrm{D}$, the main ingredients are disaccharides (DP2) and trisaccharides (DP3). Negative ion ESI-MS was also used to further determine the molecular weight of UMOS and UGOS. As shown in Figure 1E,F the main peaks 
at $351.03 \mathrm{~m} / \mathrm{z}$ and $527.04 \mathrm{~m} / \mathrm{z}$ corresponded to unsaturated alginate disaccharides and unsaturated alginate trisaccharides. These results indicated that the main ingredients of UMOS and UGOS used in this study are dimers and trimers, which are in agreement with its average molecular weights.

\subsection{Effects of AOS on Body Weight}

To evaluate the anti-obesity effects of two types of AOS, the high-fat diet obese model was established. Orlistat is the only over-the-counter drug approved by the Food and Drug Administration (FDA) to treat obesity and used as a positive control [7]. In addition, COS was also prepared and used as a positive control. According to the TLC and ESI-MS analysis, the main ingredients of COS are dimers, trimers, and tetramers (Figure S1). As shown in Figure 2A-C, the effect of COS on reducing body weight gain for HFD-induced obesity was similar to Orlistat. Several studies have shown that $\mathrm{COS}$ has an anti-obesity effect and less side effects [36]. Therefore, COS was used as a positive control to verify the anti-obesity effects of AOS, which are also functional oligosaccharides. UAOS showed a dose-dependent effect on weight loss. However, SAOS did not have a similar effect on weight loss.

To verify whether structural differences caused the different anti-obesity effects, we selected the four different types of AOS, including UAOS (UMOS and UGOS) and SAOS (SMOS and SGOS) for further studies. To assess the anti-obesity effects of AOS, the energy intake and body weight of mice were measured weekly. As shown in Figure 2D, the HFD group had slightly higher energy intake than the standard treatment diet group (STD), but the difference was not significant. The HFD foods contain more calories and this indicated that there was no influence of AOS or COS treatment on the appetite of the mice. As shown in Figure 2E, following four weeks of a high-fat diet feeding and an additional four weeks of COS or four types of AOS treatment, there was a significant difference in body weight between the STD and HFD groups. In terms of body weight gain, significant effects were seen after four weeks of UAOS treatment (UMOS: $p<0.001$ and UGOM: $p<0.01$ ) and COS treatment $(P<0.001)$. UGOM was a little less effective than UMOS $(P<0.01)$ and MOS and GOS did not show clear effects (Figure 2F). In addition, there were significant differences between COS, UMOS, and UGOM treatment groups and the HFD/STD groups. The acid hydrolyzed SAOS (MOS and GOS) treatment groups showed no difference (Figure $2 \mathrm{G}$ ). These results suggested only that the UAOS has an effective weight-loss effect in HFD mice. Meanwhile, there was no significant difference in the effects of UMOS and UGOS, which indicated that the structural difference of M and G in the C5 epimer is not the main factor in UAOS-induced alteration of body weight.

\subsection{Effect of UAOS on Serum Lipids}

In order to determine the effect of different AOS on serum lipids, four different UAOS were used and the results were analyzed, as shown in Figure 3. Compared with the STD group, there was a significant increase in TG, TC, and FFA levels, as well as a significant decrease of HDL-c, but no significant difference in LDL-c, in the HFD group. The results indicated that the HFD mice had symptoms of hyperlipidemia. The positive control, COS, clearly lowered serum TG and TC levels. Moreover, compared with SAOS (SMOS and SGOS), UAOS (UMOS and UGOM) treatment markedly lowered serum TG and TC, and decreased FFA levels. These results suggest that the enzymatic UAOS could reduce blood lipids in HFD-induced obese mice. 

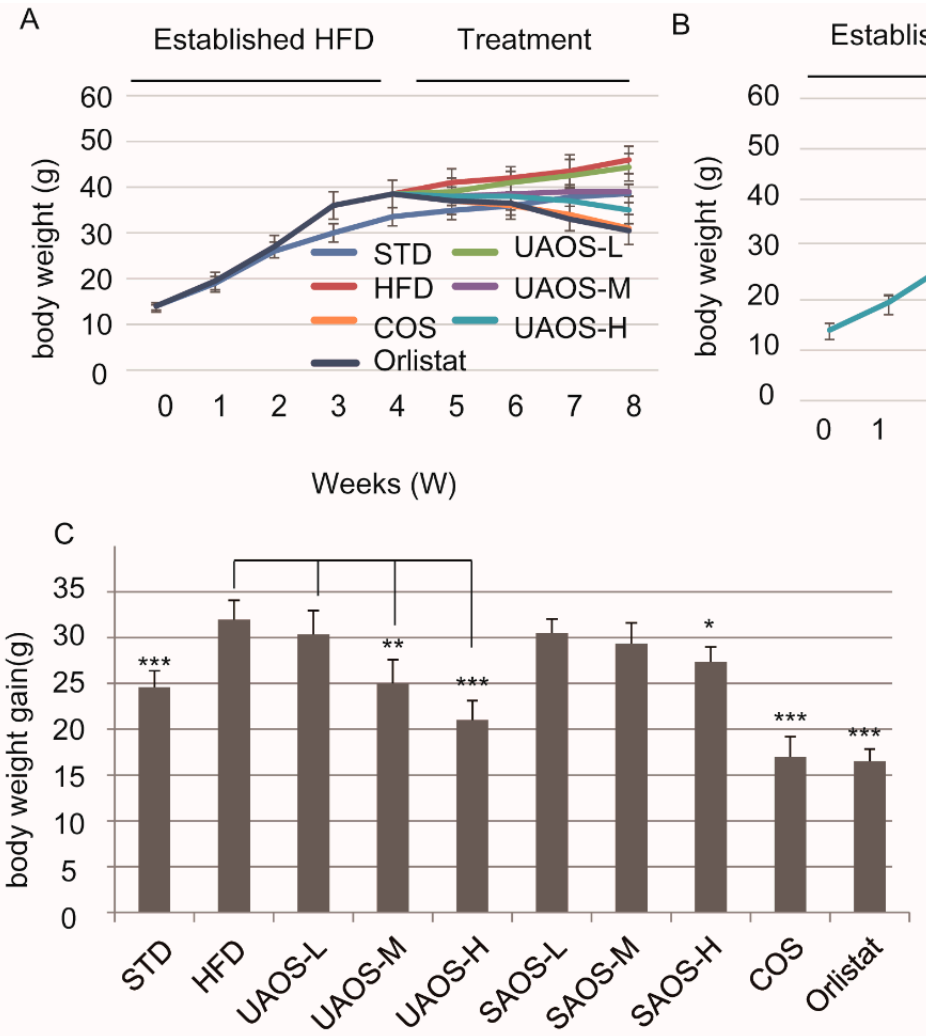

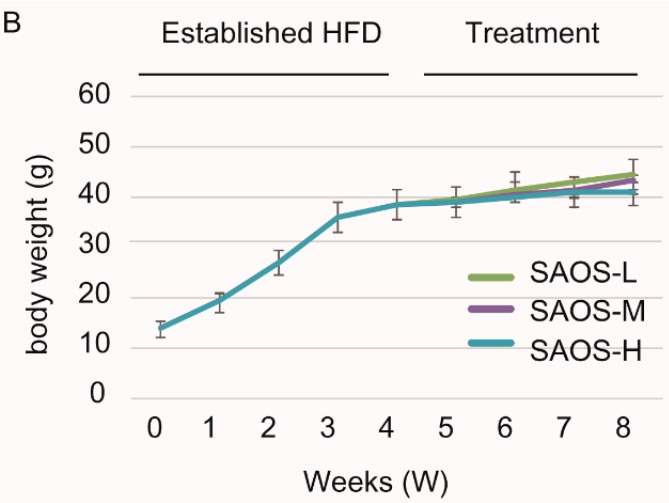

D

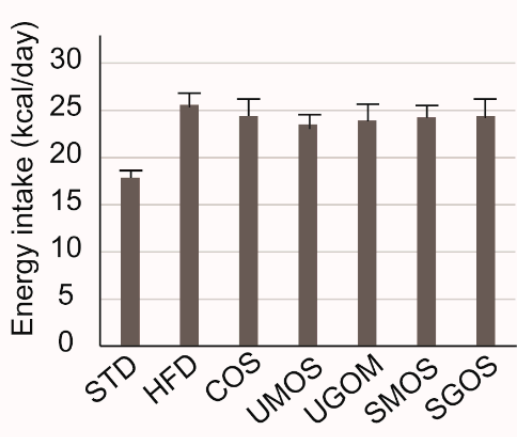

E

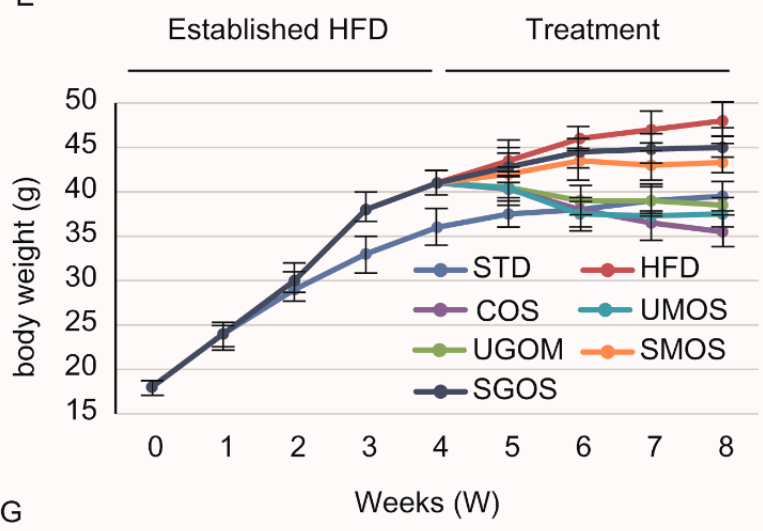

$\mathrm{F}$
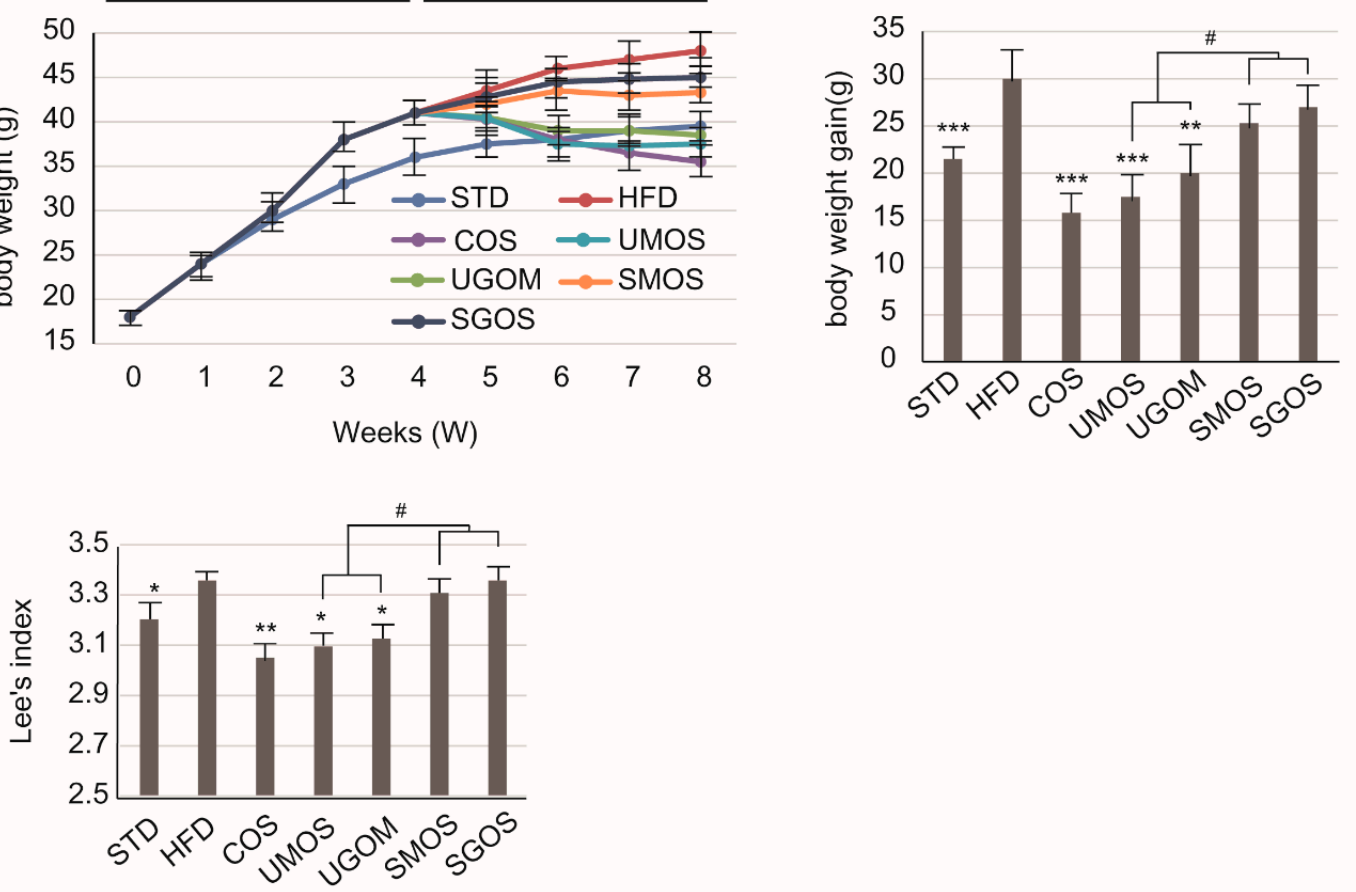

Figure 2. Changes in body weight on AOS treatment. Changes in body weight of treatment of UAOS (A) and SAOS (B), body weight gain (C) for 4 weeks. The data are represented as means \pm standard deviation (SD, $n=6)$. Changes in the energy intake (D), body weight $(\mathbf{E})$, body weight gain $(\mathbf{F})$, and Lee's index (G) during the eight-week treatment are shown. The body weight was recorded weekly. The data are represented as means \pm standard deviation (SD, $n=12)$. Compare with HFD group, ${ }^{*} p<0.05,{ }^{* *} p<0.01,{ }^{* * *} p<0.001$. Compare with indicated groups, ${ }^{*} p<0.05$. 
A
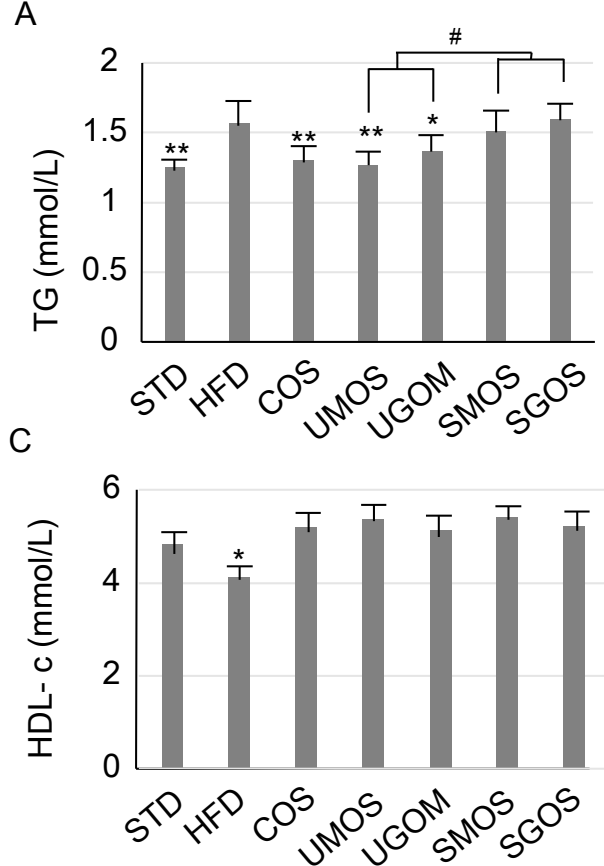

E

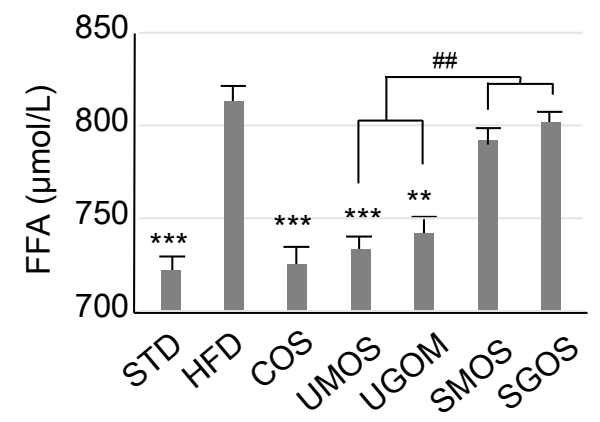

B
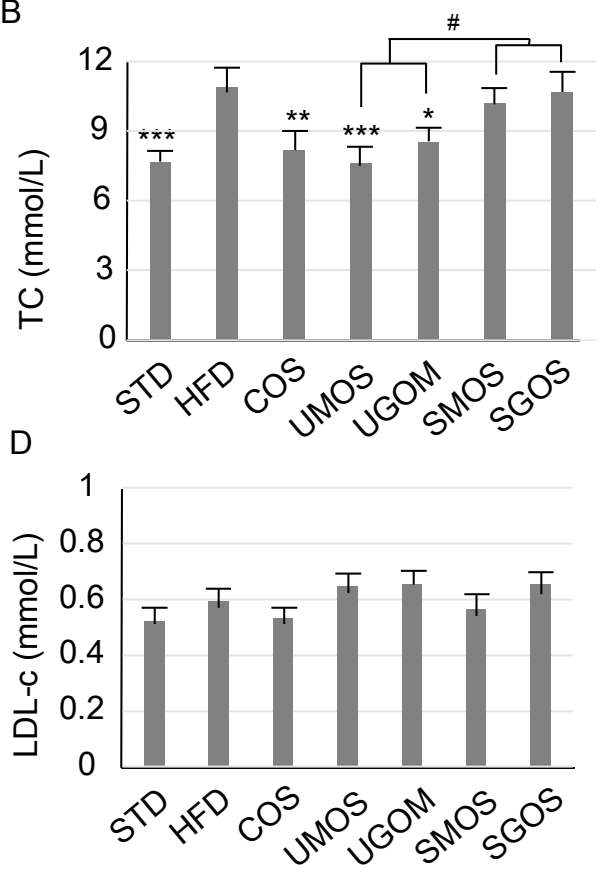

Figure 3. Changes of AOS treatment on serum lipid. TG levels (A), TC levels (B), HDL-c levels (C), LDL-c levels (D), and FFA levels (E). The data are represented as means \pm standard deviation (SD, $n=12$ ). Compare with the HFD group, ${ }^{*} p<0.05,{ }^{* *} p<0.01,{ }^{* * *} p<0.001$. Compare with indicated groups, ${ }^{\#} p<0.05,{ }^{\# \#} p<0.01$.

\subsection{Effects of UAOS on Liver Protection}

To evaluate the effect of different AOS on liver protection, the effects of UAOS on the liver were examined after eight weeks of treatment. Compared with the STD group, the liver weight (Figure 4A) of HFD-fed mice were significantly increased. Treatment with COS, UMOS $(p<0.01)$, or UGOM $(P<0.01)$ reduced HFD feeding induced liver weight. For the concentration of liver TC (Figure 4B) and TG (Figure 4C), significant increases in the HFD group were shown when compared with the STD group. This indicated that HFD feeding increased liver lipid accumulation. After treatment with UAOS (UMOS an UGOM), TC and TG levels induced in HFD feeding in the liver were significantly reduced. Moreover, the alteration of liver weight $(p<0.05)$, liver TC (UAOS and SAOS), and TG (UAOS and SAOS) caused by UAOS and SAOS treatment were significantly different (Figure 4A-C). 

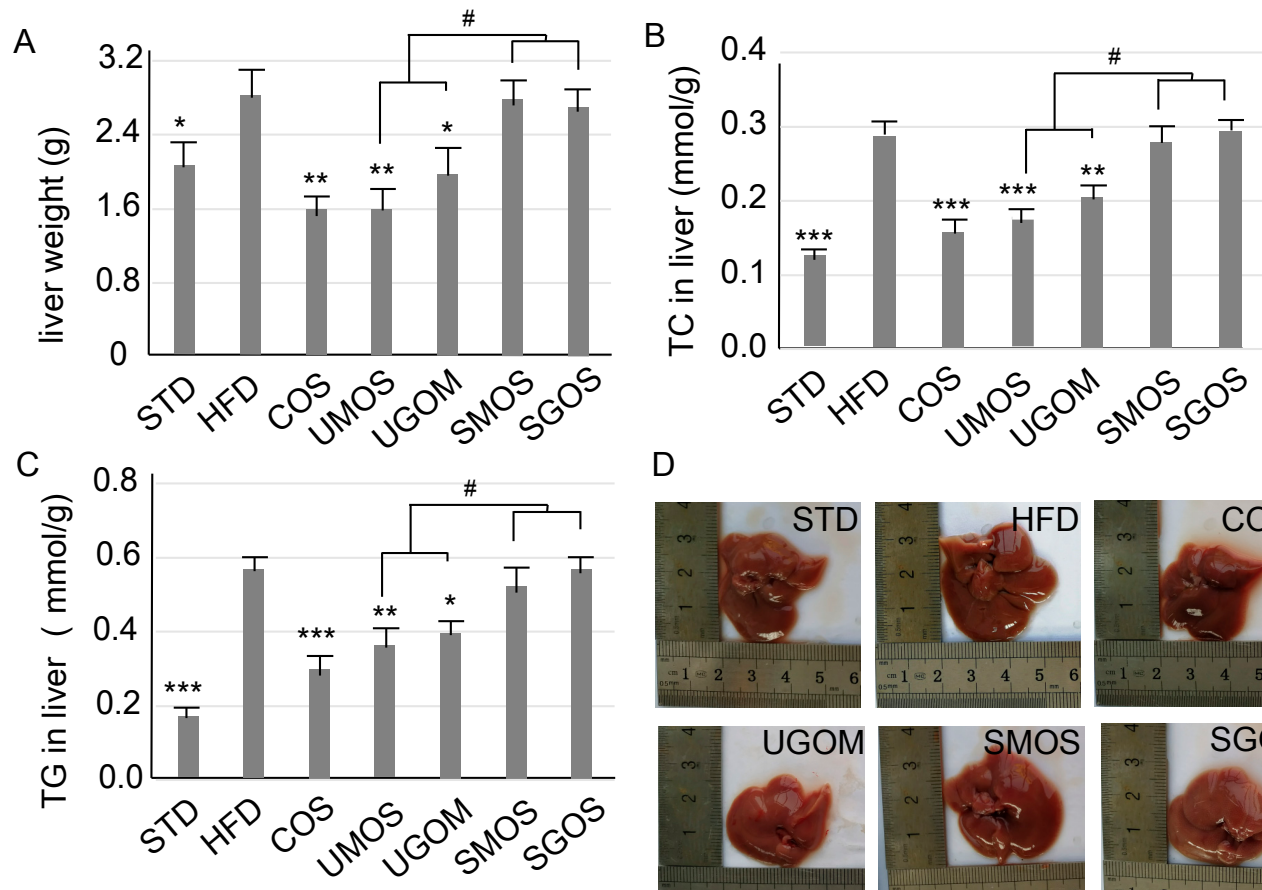

$\mathrm{D}$
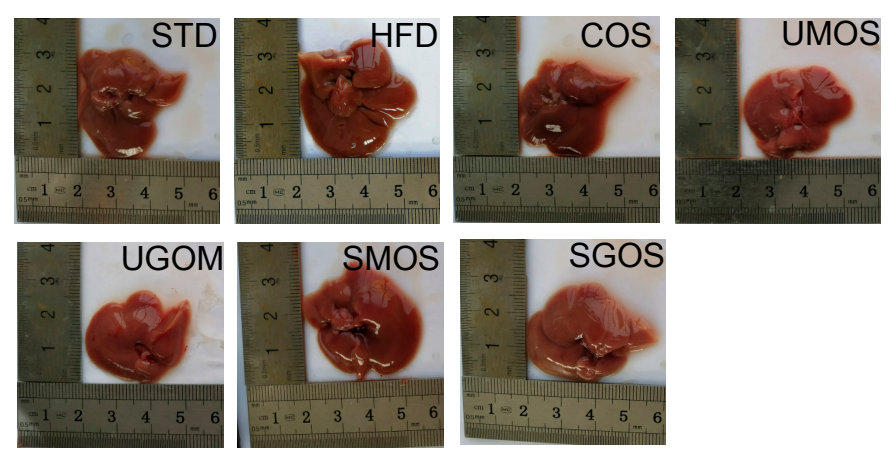

E
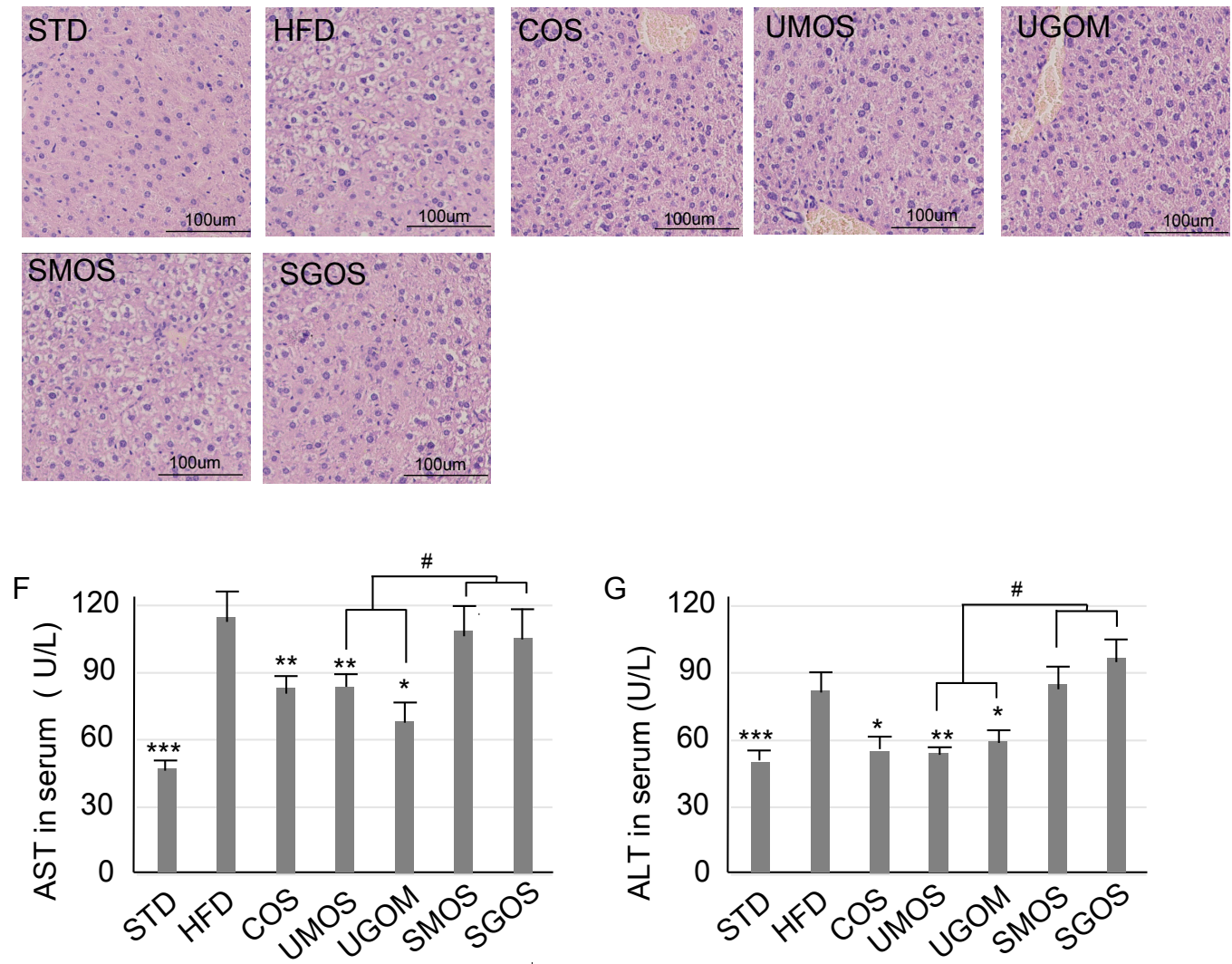

Figure 4. Changes of AOS treatment on the hepatic lipid. The whole liver weight (A), liver TC (B), and TG (C) are displayed. The whole liver morphology (D) and H\&E staining for liver tissue (E) (200X) are shown. The concentration of serum AST $(\mathbf{F})$ and ALT $(G)$ are also shown. The data are represented as means \pm standard deviation (SD, $n=12$ ). Compare with the HFD group, ${ }^{*} p<0.05,{ }^{* *} p<0.01$, *** $p<0.001$. Compare with indicated groups, ${ }^{*} p<0.05$. 
According to the liver morphology (Figure 4D), whole livers in the HFD group were much bigger than the STD group, which suggested that fatty liver had developed. According to the liver H\&E staining (Figure 4E), there were large histological abnormalities of hepatocytes in the HFD group with large fat vacuoles. This indicates that the mice had suffered a high degree of hepatic steatosis induced by the HFD. COS and UAOS markedly decreased the liver fat and fat vacuole size induced by HFD. Liver injury and hepatotoxicity are the two main factors for hyperlipidemia and obesity $[37,38]$. To further check the hepatoprotective effect of UAOS, serum AST and ALT levels were measured (Figure 4F,G). Serum AST and ALT levels were significantly increased after HFD when compared to the STD diet $(P<0.001)$. UAOS (UMOS and UGOM) significantly lowered the concentration of ALT and AST in serum. The effects of UAOS (especially UMOS) were similar to COS, which suggests that UAOS play an important role in liver protection. These results demonstrated that UAOS instead of SAOS exert a liver protective effect by reducing fat accumulation and relieving fatty liver.

To further understand the molecular mechanisms of UAOS liver protection effects, we used qPCR to measure gene expression levels of specific genes, specifically SREBP-1c, FAS, ACC, and $H M G C R$, involved in liver adipogenesis, lipogenesis, and lipolysis. In the obesity model, SREBP-1c, $F A S, A C C$, and HMGCR were increased while adiponectin was decreased in liver. Significant increases of SREBP-1c, FAS, ACC, and HMGCR and a significant decrease in adiponectin in hepatic tissue were observed in the HFD group (Figure S2). Treatment with COS and UAOS, especially UMOS, reversed the upregulated expression of SREBP-1C, FAS, ACC, and HMGCR. The downregulated expression of adiponectin was induced by HFD feeding. The results indicated that UAOS plays a critical role in hepatic lipid metabolism.

\subsection{Effects of UAOS on Adipose Tissue Mass}

The effects of UAOS (UMOS and UGOM) on adipose tissues were also examined after the eight-week administration (Figure 5). Compared with the STD fed mice, the weights of epididymal (Figure 5A), mesenteric (Figure 5B), perirenal white adipose tissues (WAT) (Figure 5C), and adipocyte size (Figure 5D) in the HFD group were markedly increased. In addition, UAOS were found to reduce the weights of epididymal, mesenteric, perirenal WAT and adipocyte size caused by an HFD. Moreover, the inhibitory effects of UMOS on HFD-induced elevated adipose tissue mass were similar to that of COS. Moreover, according to the morphology of epididymal WAT, the size of WAT in HFD mice was higher than in the STD group (Figure 5E) and, according to the H\&E staining of WAT, the size of adipocytes from HFD mice were bigger than in the STD group (Figure 5F). Treatment with COS and the two UAOS (UMOS and UGOM) inhibited the growth of adipocytes and the size of adipose tissue, since smaller epididymal WAT and smaller adipocytes were observed when compared to mice in the HFD group (Figure 5E,F). Therefore, UAOS can play an effective anti-obesity role by inhibiting the growth of adipocytes. 

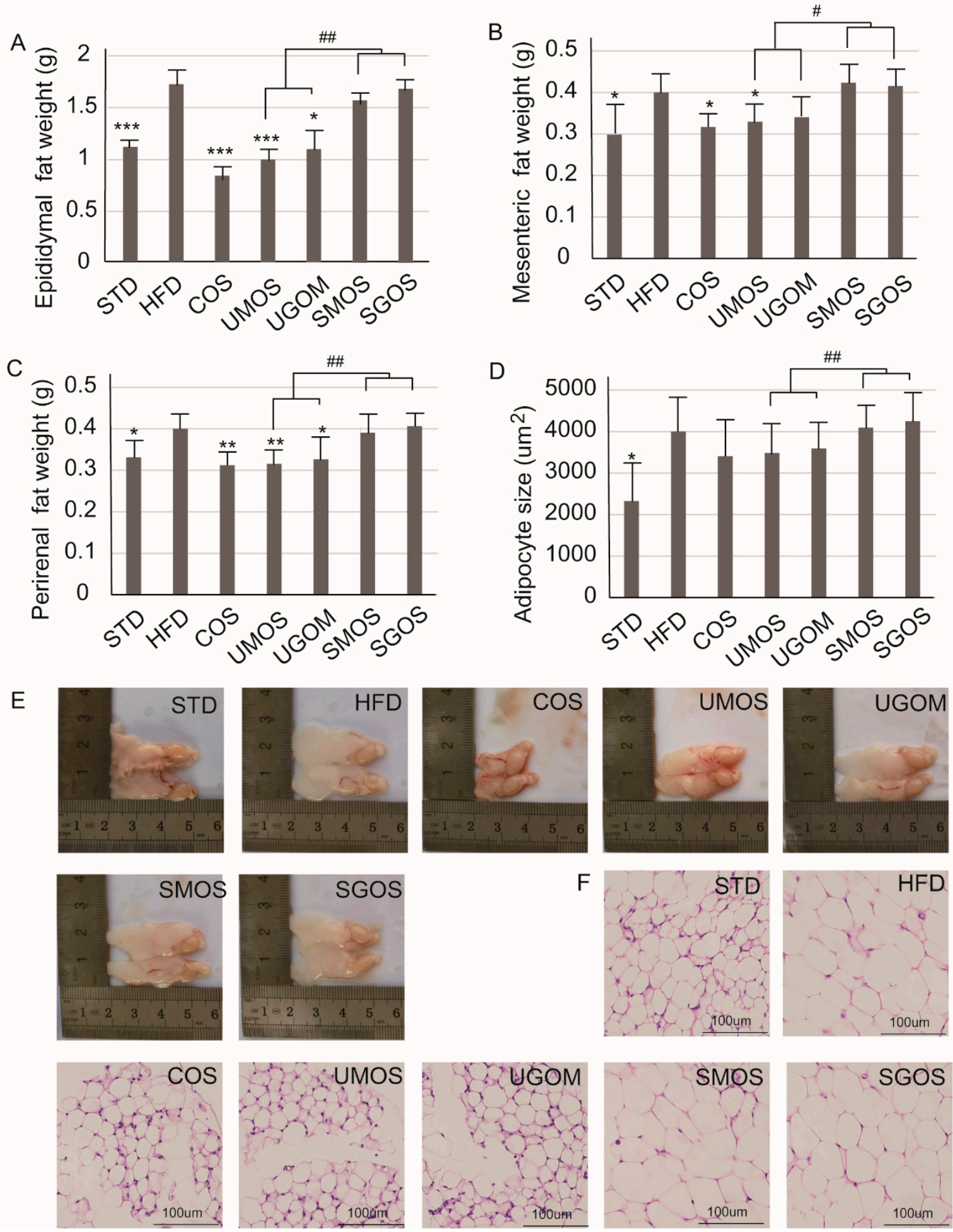

Figure 5. Changes of UAOS treatment on adipocytes in adipose mass. The fat mass of epididymal (A), mesenteric (B), perirenal tissues (C), adipocyte size (D), the whole WAT (E), and WAT tissue stained by H\&E staining $(200 \times)(\mathbf{F})$ are shown in the figure. The data are represented as means \pm standard deviation (SD, $n=12$ ). Compare with the HFD group, ${ }^{*} p<0.05,{ }^{* *} p<0.01,{ }^{* * *} p<0.001$. Compare with indicated groups, ${ }^{\#} p<0.05,{ }^{\#} p<0.01$.

WAT is a type of adipose tissue whose main function is to store excess fat in the body, which leads to obesity. Hyperplasia and hypertrophy of WAT can lead to obesity and metabolic syndrome $[39,40]$. 
Therefore, inhibiting the formation of WAT is an effective strategy for the treatment of obesity. In the obesity model, PPAR $\gamma, C / E B P \alpha, S T R E B P-1 c, A C C, F A B P 4, F A S$, and HSL were increased while PLIN was decreased in WAT. In this study, we also measured gene expression levels of specific genes including $P P A R \gamma, C / E B P \alpha, S T R E B P-1 c, A C C, F A B P 4, F A S, H S L$, and PLIN in WAT. Significant increases in PPAR $\gamma$, C/EBP $\alpha, S T R E B P-1 c, A C C, F A B P 4, F A S$, and PLIN and a significant decrease in HSL expression in WAT tissue was observed in the HFD group (Figure S3). Treatment with COS and UAOS, especially UMOS, reversed the upregulated expression of PPAR $\gamma, S T R E B P-1 C, A C C, F A B P 4, F A S$, and PLIN, and the downregulated expression of HSL was induced by HFD feeding. However, there was no effect on the expression of $C / E B P \alpha$ following COS or UAOS administration. These results indicated that UAOS plays a critical role in lipid accumulation in epididymal WAT. The above results also showed that changes in gene expression related to lipid metabolism in the liver and WAT suggest that UAOS can inhibit adipogenesis in the liver and WAT to reduce obesity.

\subsection{Effects of UAOS on Liver Hydrogen Peroxide and Malondialdehyde Level}

In this study, UAOS showed excellent hepatoprotective and anti-obesity effects, but acid hydrolyzed SAOS showed no effect on HFD-fed mice. Since the structural difference between UAOS and SAOS is an unsaturated bond, we further tested their antioxidant capabilities. An HFD increased hepatic generation of hydrogen peroxide, as well as increasing hepatic ROS levels compared with the STD diet group (Figure 6). Compared with the HFD control group, treatment with UAOS significantly lowered hepatic hydrogen peroxide (UMOS: 42.1\% and UGOM: 25.3\%, Figure 6A) and malondialdehyde (MDA) levels (UMOS: 28.5\% and UGOM: 24.7\%, Figure 6B). Moreover, the difference between UAOS (UMOS and UGOM) and SAOS (SMOS and SGOS) caused an alteration of liver hydrogen peroxide $(p<0.05)$. Liver MDA $(p<0.01)$ were significant. These results indicate that UAOS have the potential to alleviate HFD-induced ROS formation and accumulation.
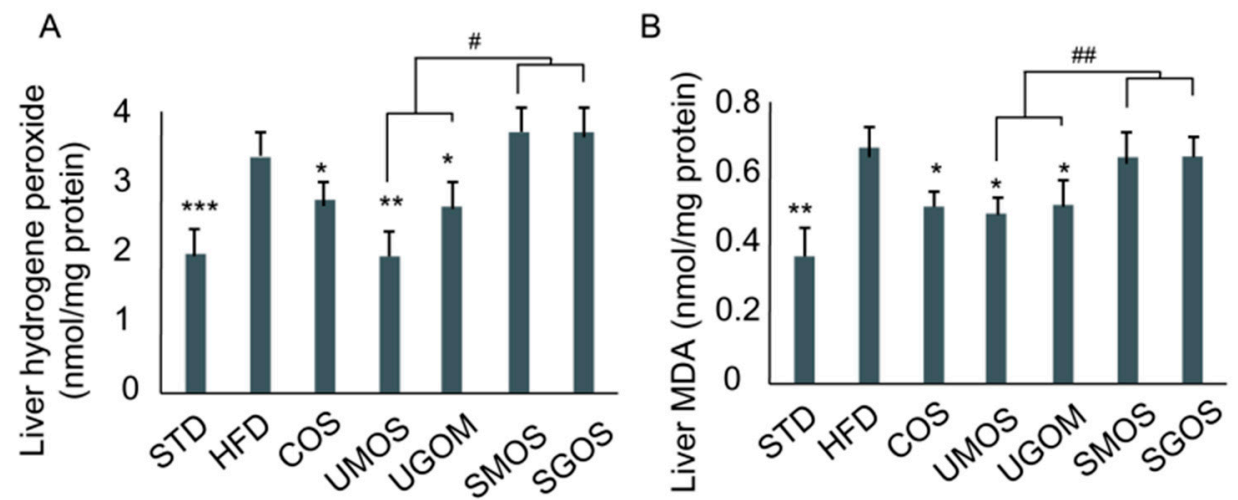

Figure 6. The effect of AOS treatment on hepatic $\mathrm{H}_{2} \mathrm{O}_{2}$ level (A) and liver MDA level (B) in mice fed a high fat diet for 8 weeks. The data are represented as means \pm standard deviation (SD, $n=12)$. Compare with the HFD group, ${ }^{*} p<0.05,{ }^{* *} p<0.01,{ }^{* * *} p<0.001$. Compare with indicated groups, ${ }^{\#} p<0.05,{ }^{\# \#} p<0.01$.

\subsection{Effects of $U A O S$ on AMPK Signaling}

AMPK is an important cellular energy sensor that can regulate energy metabolism. AMPK $\alpha$ is the main catalytic subunit in WAT tissue and enhances lipid metabolism after phosphorylation on Thr-172 [41-43]. Therefore, the activation of AMPK and its downstream signaling protein ACC in WAT tissues were detected using Western blotting (Figure 7A,B). Protein expression levels of p-AMPK and p-ACC in the HFD group were significantly decreased compared to the STD group. Treatment with UAOS significantly reversed the inactivation of AMPK and ACC (especially UMOS). These results suggested that UAOS (especially UMOS) administration could improve obesity by activating AMPK 
and the ACC signaling pathway to enhance lipid catabolism. Based on these results, we have proposed a mechanism by which UAOS causes effects of hepatoprotection and anti-obesity (Figure 7C).
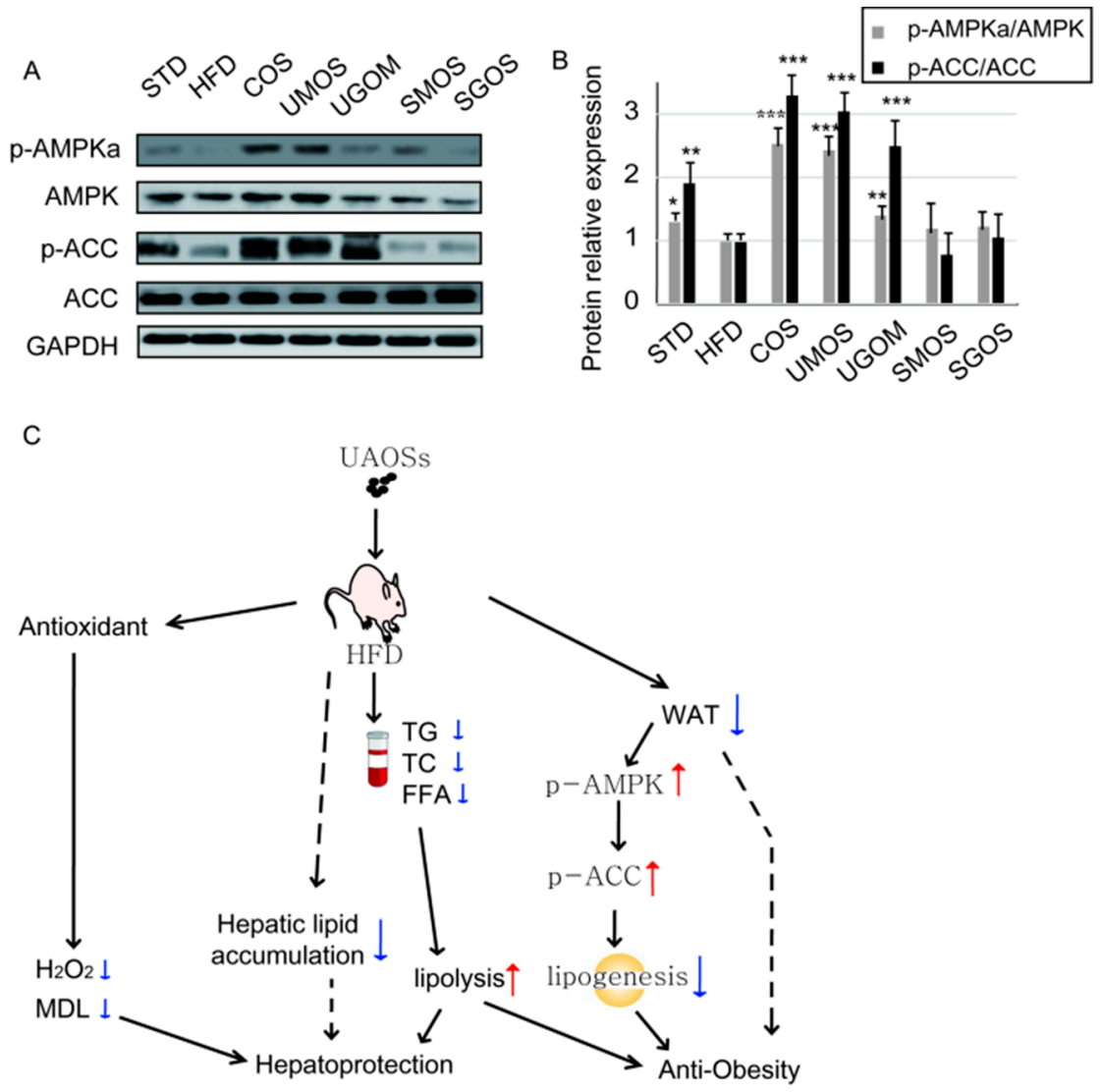

Figure 7. UAOS activated the AMPK signaling pathway in WAT. (A) The protein expression level of AMPK, p-AMPK, ACC, and p-ACC in WAT were detected by Western blotting. (B) The relative protein levels were quantified. (C) The proposed mechanism by which AOS causes effects of hepatoprotection and anti-obesity. The data are represented as means \pm standard deviation $(\mathrm{SD}, n=3) .{ }^{*} p<0.05$, $* * p<0.01, * * * 00.001$.

\section{Discussion}

Obesity and its co-morbidities seriously threaten human health [44]. Since existing anti-obesity drugs have strong side effects, the development of functional foods as adjuvant treatments is urgently needed $[6,45]$. In this study, we investigated the use of a non-toxic green food additive, UAOS, from the enzymatic degradation of LJ, which showed effective anti-obesity effects in an HFD-mouse model. As documented previously, AOS have been reported to have various biological functions, such as anti-oxidant activity, immunomodulatory effect, and anti-tumor activity [45-48]. However, to the best of our knowledge, this is the first report about anti-obesity activity of AOS. The structural differences are often accompanied by changes in biological activity [49]. Subdivide the structures of AOS components. Four types of AOS are determined, including acid hydrolyzed SAOS (SMOS and SGOS) and enzymatic UAOS (UMOS and UGOS). M and G are epimers in C5. Our results indicate that the structural difference of $\mathrm{M}$ and $\mathrm{G}$ does not result in significantly different functions in terms of hepatoprotective and anti-obesity activity (Figures $2-5$ ). This study indicated that, compared with SAOS, the UAOS showed a significantly anti-obesity effect (Figure 2). The discovery of these excellent biological activities of enzymatic UAOS will promote the development of green processing methods for brown seaweeds. 
In a previous study, compared with SAOS, the non-reducing ends of UAOS provide double bonds between $\mathrm{C} 4$ and $\mathrm{C} 5$, giving them greater in vitro anti-oxidant activity than ascorbic acid in lipid oxidation treatment [46]. This study showed that UAOS also played effective anti-oxidant activity in vivo tissue (Figure 6). This excellent characteristics make UAOS reduce excessive ROS accumulation, which maintains mitochondrial homeostasis. Obesity leads to metabolic stress resulting in liver injury, including non-alcoholic fatty liver disease (NAFLD). Therefore, efforts to reduce fat mass for preventing and treating NAFLD have been sought $[50,51]$. Our results indicate that UAOS treatment significantly reduced the concentration of ALT and AST in serum and played a role in liver protection by reducing fat accumulation and relieving fatty liver. In NAFLD, oxidative stress and dysfunction of mitochondria are linked with disorders in $\beta$-oxidation of free fatty acids [52,53]. Excessive liver ROS production and decreased cellular antioxidant activity lead to oxidative stress and liver oxidative damage [21]. In addition, it has shown that obese, high glucose-fed rats showed increases in plasma levels of triglycerides, superoxide anion production, and NADPH oxidase activity in the adipose tissue [54]. Moreover, argan oil as an antioxidant diet was found to reduce the HFD or high glucose diet, which induced an increase in adipose tissue weight, body weight, and serum triglyceride concentrations. This suggests that adipose tissue oxidative stress is partly implicated in developing visceral obesity $[54,55]$. Therefore, antioxidants can effectively improve lipid and ROS metabolism, which, thereby, reduces liver steatosis and oxidative damage. This study also showed that UAOS have better hepatoprotective activity than SAOS (Figure 4), which corresponds to their anti-oxidant activity. However, due to increased adipose tissue leading to obesity, whether HFD induced oxidative stress is related to obesity development in our animal model. If AOSs exert beneficial impacts on obesity through their effects on adipose tissue oxidative stress, which need to be further studied.

Fat accumulation in adipose tissues induced by a high-fat diet is one of the causes of obesity. Adipocytes play an important role in energy regulation and energy metabolism. Our results showed that UAOS significantly reduced the growth of adipocytes, which suggests excellent anti-obesity effects. Simultaneously, UAOS also reduced serum TG, TC, and FFA levels caused by high fat diets, which also contribute to its anti-obesity effects. AMPK is an important energy sensor that modulates energy balance and lipid metabolism. Our results showed that UAOS treatment increased AMPK activation (Figure 7). Therefore, the anti-obesity effect of UAOS works by regulating the AMPK signaling pathway. Several studies have reported that AMPK plays a central role in regulating glucose and lipid metabolism. It has previously been reported that AMPK activation inhibits lipogenesis and adipocyte differentiation. Furthermore, ACC as downstream of AMPK is a multi-subunit enzyme that regulates enzymes involved in malonyl-CoA production, fatty acid synthesis, and fatty acid oxidation in adipocyte $[56,57]$.

\section{Conclusions}

In this study, UAOS as a non-toxic green food showed effective anti-obesity effects in an HFD-fed mice model. UAOS could significantly increase both AMPK and ACC phosphorylation in adipocytes, which indicated that UAOS played an anti-obesity effect through the AMPK signaling pathway. These results make UAOS a good candidate for adjuvant therapy in anti-obesity treatment. Further work will focus on the molecular mechanism in cell lines and the gut microbiota change met of its anti-obesity activity.

Supplementary Materials: The following are available online at http://www.mdpi.com/1660-3397/17/9/540/s1. Figure S1: TLC analysis (A) and positive-ion ESI-MS analysis (B) of prepared COS. Figure S2: Effect of UAOS on the expression of lipid-related genes in liver. Figure S3: Effect of UAOS on the expression of lipid-related genes in epididymal WAT. Table S1: The primers sequences used for a PCR reaction.

Author Contributions: S.L. and N.H. conceived the study and designed experiments. S.L. supervised all research and revised the manuscript. L.W., N.H., and S.L. carried out the animal and chemical experiments, respectively, analyzed the data, and contributed equally to the study. S.L. performed the chemical analysis of chemicals. 
Funding: The National Nature Science Foundation of China, grant number 31900031, the National Nature Science Foundation of China, grant number 81602621, and the National Nature Science Foundation of Shandong Provence, grant number ZR2019BD027, funded this research.

Conflicts of Interest: The authors declare no conflict of interest.

\section{References}

1. Chen, J.; Huang, W.; Zhang, T.; Lu, M.; Jiang, B. Anti-obesity potential of rare sugar D-psicose by regulating lipid metabolism in rats. Food Funct. 2019. [CrossRef] [PubMed]

2. World Health Organization. Global Report on Diabetes; World Health Organization: Geneva, Switzerland, 2016; Available online: http://www.who.int/diabetes/global-report (accessed on 21 August 2019).

3. Chu, D.T.; Minh, N.N.; Dinh, T.C.; Thai, N.L.; Nguyen, K.H.; Nhu, V.N.; Tao, Y.; Son, L.H.; Le, D.H.; Nga, V.B. An update on physical health and economic consequences of overweight and obesity. Diabetes Metab. Syndr. 2018, 12, 1095-1100. [CrossRef] [PubMed]

4. Polyzos, S.A.; Kountouras, J.; Mantzoros, C.S. Obesity and nonalcoholic fatty liver disease: From pathophysiology to therapeutics. Metab. Clin. Exp. 2019, 92, 82-97. [CrossRef] [PubMed]

5. Cheung, B.M. Rise and fall of anti-obesity drugs. World J. Diabetes 2011, 2, 19-23.

6. Fragkiadakis, G.A.; Toutoudaki, M.; Tsatsakis, A. Anti-obesity drugs: The role of dieticians in monitoring side effects and toxicity. Toxicol. Lett. 2010, 196, S101. [CrossRef]

7. Saunders, K.H.; Umashanker, D.; Igel, L.I.; Kumar, R.B.; Aronne, L.J. Obesity Pharmacotherapy. Med. Clin. North Am. 2018, 102, 135-148. [CrossRef]

8. Florez-Fernandez, N.; Torres, M.D.; Gonzalez-Munoz, M.J.; Dominguez, H. Recovery of bioactive and gelling extracts from edible brown seaweed Laminaria ochroleuca by non-isothermal autohydrolysis. Food Chem. 2019, 277, 353-361. [CrossRef]

9. Yang, H.S.; Haj, F.G.; Lee, M.; Kang, I.; Zhang, G.; Lee, Y. Laminaria japonica Extract Enhances Intestinal Barrier Function by Altering Inflammatory Response and Tight Junction-Related Protein in Lipopolysaccharide-Stimulated Caco-2 Cells. Nutrients 2019, 11, 1001. [CrossRef]

10. Walsh, P.J.; McGrath, S.; McKelvey, S.; Ford, L.; Sheldrake, G.; Clarke, S.A. The Osteogenic Potential of Brown Seaweed Extracts. Mar. Drugs 2019, 17, 141. [CrossRef]

11. Wargacki, A.J.; Leonard, E.; Win, M.N.; Regitsky, D.D.; Santos, C.N.; Kim, P.B.; Cooper, S.R.; Raisner, R.M.; Herman, A.; Sivitz, A.B.; et al. An engineered microbial platform for direct biofuel production from brown macroalgae. Science 2012, 335, 308-313. [CrossRef]

12. Enquist-Newman, M.; Faust, A.M.; Bravo, D.D.; Santos, C.N.; Raisner, R.M.; Hanel, A.; Sarvabhowman, P.; Le, C.; Regitsky, D.D.; Cooper, S.R.; et al. Efficient ethanol production from brown macroalgae sugars by a synthetic yeast platform. Nature 2014, 505, 239-243. [CrossRef] [PubMed]

13. Lee, K.Y.; Mooney, D.J. Alginate: Properties and biomedical applications. Prog. Polym. Sci. 2012, 37, $106-126$. [CrossRef] [PubMed]

14. Falkeborg, M.; Cheong, L.Z.; Gianfico, C.; Sztukiel, K.M.; Kristensen, K.; Glasius, M.; Xu, X.; Guo, Z. Alginate oligosaccharides: Enzymatic preparation and antioxidant property evaluation. Food Chem. 2014, 164, $185-194$. [CrossRef] [PubMed]

15. Ueno, M.; Hiroki, T.; Takeshita, S.; Jiang, Z.; Kim, D.; Yamaguchi, K.; Oda, T. Comparative study on antioxidative and macrophage-stimulating activities of polyguluronic acid (PG) and polymannuronic acid (PM) prepared from alginate. Carbohydr. Res. 2012, 352, 88-93. [CrossRef] [PubMed]

16. Küpper, F.C.; Müller, D.G.; Peters, A.F.; Kloareg, B.; Potin, P. Oligoalginate recognition and oxidative burst play a key role in natural and induced resistance of sporophytes of laminariales. J. Chem. Ecol. 2002, 28, 2057-2081. [CrossRef] [PubMed]

17. Iwamoto, Y.; Xu, X.; Tamura, T.; Oda, T.; Muramatsu, T. Enzymatically depolymerized alginate oligomers that cause cytotoxic cytokine production in human mononuclear cells. J. Agric. Chem. Soc. Jpn. 2003, 67, 258-263. [CrossRef]

18. Tusi, S.K.; Khalaj, L.; Ashabi, G.; Kiaei, M.; Khodagholi, F. Alginate oligosaccharide protects against endoplasmic reticulum- and mitochondrial-mediated apoptotic cell death and oxidative stress. Biomaterials 2011, 32, 5438-5458. [CrossRef] 
19. Li, S.Y.; Wang, Z.P.; Wang, L.N.; Peng, J.X.; Wang, Y.N.; Han, Y.T.; Zhao, S.F. Combined enzymatic hydrolysis and selective fermentation for green production of alginate oligosaccharides from Laminaria japonica. Bioresour. Technol. 2019, 281, 84-89. [CrossRef]

20. Canon Barroso, L.; Diaz Herrera, N.; Calvo Hueros, J.I.; Cruces Muro, E.; Nieto Hernandez, T.; Buitrago Ramirez, F. Incidence of cardiovascular disease and validity of equations of coronary risk in diabetic patients with metabolic syndrome. Med. Clin. (Barc) 2007, 128, 529-535.

21. Shchelochkov, O.A.; Li, F.Y.; Geraghty, M.T.; Gallagher, R.C.; Van Hove, J.L.; Lichter-Konecki, U.; Fernhoff, P.M.; Copeland, S.; Reimschisel, T.; Cederbaum, S.; et al. High-frequency detection of deletions and variable rearrangements at the ornithine transcarbamylase (OTC) locus by oligonucleotide array CGH. Mol. Genet. Metab. 2009, 96, 97-105. [CrossRef]

22. Herzig, S.; Shaw, R.J. AMPK: Guardian of metabolism and mitochondrial homeostasis. Nat. Rev. Mol. Cell Biol. 2018, 19, 121-135. [CrossRef] [PubMed]

23. Liu, H.; Wang, J.; Liu, M.; Zhao, H.; Yaqoob, S.; Zheng, M.; Cai, D.; Liu, J. Antiobesity Effects of Ginsenoside Rg1 on 3T3-L1 Preadipocytes and High Fat Diet-Induced Obese Mice Mediated by AMPK. Nutrients 2018, 10, 830. [CrossRef] [PubMed]

24. Kim, S.K.; Kong, C.S. Anti-adipogenic effect of dioxinodehydroeckol via AMPK activation in 3T3-L1 adipocytes. Chem.-Biol. Interact. 2010, 186, 24-29. [CrossRef] [PubMed]

25. Han, M.H.; Jeong, J.S.; Jeong, J.W.; Choi, S.H.; Kim, S.O.; Hong, S.H.; Park, C.; Kim, B.W.; Choi, Y.H. Ethanol extracts of Aster yomena (Kitam.) Honda inhibit adipogenesis through the activation of the AMPK signaling pathway in 3T3-L1 preadipocytes. Drug Discov. Ther. 2017, 11, 281-287. [CrossRef] [PubMed]

26. Kang, S.W.; Kang, S.I.; Shin, H.S.; Yoon, S.; Kim, J.H.; Ko, H.C.; Kim, S.J. Sasa quelpaertensis Nakai extract and its constituent p-coumaric acid inhibit adipogenesis in 3T3-L1 cells through activation of the AMPK pathway. Food Chem. Toxicol. 2013, 59, 380-385. [CrossRef]

27. Jin, R.; Minsook, K.; You, M.K.; Bang, M.A.; Hyeona, K. Pear pomace water extract inhibits adipogenesis and induces apoptosis in 3T3-L1 adipocytes. Nutr. Res. Pract. 2014, 8, 33.

28. Haug, A.; Larsen, B.; Smidsrod, O. A study of the constitution of alginic acid by partial acid hydrolysis. Proc. Fifth Int. Seaweed Symp. Halifax August 1966, 20, 271-277.

29. Wang, Y.; Chen, X.; Bi, X.; Ren, Y.; Han, Q.; Zhou, Y.; Han, Y.; Yao, R.; Li, S. Characterization of an Alkaline Alginate Lyase with pH-Stable and Thermo-Tolerance Property. Mar. Drugs 2019, 17, 308. [CrossRef]

30. Li, S.; Wang, L.; Chen, X.; Zhao, W.; Sun, M.; Han, Y. Cloning, Expression, and Biochemical Characterization of Two New Oligoalginate Lyases with Synergistic Degradation Capability. Mar. Biotechnol. 2018, 20, 75-86. [CrossRef]

31. Li, S.; Wang, L.; Hao, J.; Xing, M.; Sun, J.; Sun, M. Purification and Characterization of a New Alginate Lyase from Marine Bacterium Vibrio sp. SY08. Mar. Drugs 2017, 15, 1. [CrossRef]

32. Zhou, Y.; Chen, X.; Li, X.; Han, Y.; Wang, Y.; Yao, R.; Li, S. Purification and Characterization of A New Cold-Adapted and Thermo-Tolerant Chitosanase from Marine Bacterium Pseudoalteromonas sp. SY39. Molecules 2019, 24, 183. [CrossRef]

33. Brown-Borg, H.; Johnson, W.T.; Rakoczy, S.; Romanick, M. Mitochondrial oxidant generation and oxidative damage in Ames dwarf and GH transgenic mice. J. Am. Aging Assoc. 2001, 24, 85-96. [CrossRef]

34. Gonenc, A.; Ozkan, Y.; Torun, M.; Simsek, B. Plasma malondialdehyde (MDA) levels in breast and lung cancer patients. J. Clin. Pharm. Ther. 2001, 26, 141-144. [CrossRef]

35. Song, J.; Ma, Q.; Hu, M.; Qian, D.; Wang, B.; He, N. The Inhibition of miR-144-3p on Cell Proliferation and Metastasis by Targeting TOP2A in HCMV-Positive Glioblastoma Cells. Molecules 2018, 23, 3259. [CrossRef]

36. Pan, H.; Fu, C.; Huang, L.; Jiang, Y.; Deng, X.; Guo, J.; Su, Z. Anti-Obesity Effect of Chitosan Oligosaccharide Capsules (COSCs) in Obese Rats by Ameliorating Leptin Resistance and Adipogenesis. Mar. Drugs 2018, 16, 198. [CrossRef]

37. Ghali, P.; Lindor, K.D. Hepatotoxicity of drugs used for treatment of obesity and its comorbidities. Semin. Liver Dis. 2004, 24, 389-397. [CrossRef]

38. Massart, J.; Begriche, K.; Moreau, C.; Fromenty, B. Role of nonalcoholic fatty liver disease as risk factor for drug-induced hepatotoxicity. J. Clin. Transl. Res. 2017, 3, 212-232.

39. Achike, F.I.; To, N.H.P.; Wang, H.; Kwan, C.Y. Obesity, metabolic syndrome, adipocytes and vascular function: A holistic viewpoint. Clin. Exp. Pharmacol. Physiol. 2011, 38, 1-10. [CrossRef] 
40. Park, Y.K.; Park, B.; Lee, S.; Choi, K.; Moon, Y.; Park, H. Hypoxia-inducible Factor-2 $\alpha$-dependent Hypoxic Induction of Wnt10b Expression in Adipogenic Cells. J. Biol. Chem. 2013, 288, 26311-26322. [CrossRef]

41. Ceddia, R.B. The role of AMP-activated protein kinase in regulating white adipose tissue metabolism. Mol. Cell. Endocrinol. 2013, 366, 194-203. [CrossRef]

42. Gaidhu, M.P.; Ceddia, R.B. Remodeling glucose and lipid metabolism through AMPK activation: Relevance for treating obesity and Type 2 diabetes. Clin. Lipidol. 2009, 4, 465-477. [CrossRef]

43. Xu, J.; Donepudi, A.C.; Moscovitz, J.E.; Slitt, A.L. Keap1-Knockdown Decreases Fasting-Induced Fatty Liver via Altered Lipid Metabolism and Decreased Fatty Acid Mobilization from Adipose Tissue. PLoS ONE 2013, 8, e79841. [CrossRef]

44. Baboota, R.K.; Bishnoi, M.; Ambalam, P.; Kondepudi, K.K.; Sarma, S.M.; Boparai, R.K.; Podili, K. Functional food ingredients for the management of obesity and associated co-morbidities-A review. J. Funct. Foods 2013, 5, 997-1012. [CrossRef]

45. Nathan, P.J.; O’Neill, B.V.; Napolitano, A.; Bullmore, E.T. Neuropsychiatric adverse effects of centrally acting antiobesity drugs. CNS Neurosci. Ther. 2011, 17, 490-505. [CrossRef]

46. Guo, J.J.; Ma, L.L.; Shi, H.T.; Zhu, J.B.; Wu, J.; Ding, Z.W.; An, Y.; Zou, Y.Z.; Ge, J.B. Alginate Oligosaccharide Prevents Acute Doxorubicin Cardiotoxicity by Suppressing Oxidative Stress and Endoplasmic Reticulum-Mediated Apoptosis. Mar. Drugs 2016, 14, 231. [CrossRef]

47. Khodagholi, F.; Ashabi, G.; Tusi, S.K.; Khalaj, L.; Kiaei, M. Alginate oligosaccharide protects against $\mathrm{H}_{2} \mathrm{O}_{2}$ -induced endoplasmic reticulum- and mitochondrial-mediated apoptotic cell death. Alzheimers Dement. 2011, 7, S613. [CrossRef]

48. Yang, Y.; Ma, Z.; Yang, G.; Wan, J.; Li, G.; Du, L.; Lu, P. Alginate oligosaccharide indirectly affects toll-like receptor signaling via the inhibition of microRNA-29b in aneurysm patients after endovascular aortic repair. Drug Design. Dev. Ther. 2017, 11, 2565-2579. [CrossRef]

49. Zhou, R.; Shi, X.Y.; Bi, D.C.; Fang, W.S.; Wei, G.B.; Xu, X. Alginate-Derived Oligosaccharide Inhibits Neuroinflammation and Promotes Microglial Phagocytosis of beta-Amyloid. Mar. Drugs 2015, 13, 5828-5846. [CrossRef]

50. Sung, K.C.; Jeong, W.S.; Wild, S.H.; Byrne, C.D. Combined influence of insulin resistance, overweight/obesity, and fatty liver as risk factors for type 2 diabetes. Diabetes Care 2012, 35, 717-722. [CrossRef]

51. Loomba, R.; Abraham, M.; Unalp, A.; Wilson, L.; Lavine, J.; Doo, E.; Bass, N.M.; Nonalcoholic Steatohepatitis Clinical Research Network. Association between diabetes, family history of diabetes, and risk of nonalcoholic steatohepatitis and fibrosis. Hepatology 2012, 56, 943-951. [CrossRef]

52. Savini, I.; Catani, M.V.; Evangelista, D.; Gasperi, V.; Avigliano, L. Obesity-associated oxidative stress: Strategies finalized to improve redox state. Int. J. Mol. Sci. 2013, 14, 10497-10538. [CrossRef]

53. Annamalai, S.; Mohanam, L.; Raja, V.; Dev, A.; Prabhu, V. Antiobesity, antioxidant and hepatoprotective effects of Diallyl trisulphide (DATS) alone or in combination with Orlistat on HFD induced obese rats. Biomed. Pharmacother. Biomed. Pharmacother. 2017, 93, 81-87. [CrossRef]

54. El Midaoui, A.; Haddad, Y.; Filali-Zegzouti, Y.; Couture, R. Argan Oil as an Effective Nutri-Therapeutic Agent in Metabolic Syndrome: A Preclinical Study. Int. J. Mol. Sci. 2017, 18, 2492. [CrossRef]

55. Sour, S.; Belarbi, M.; Sari, N.; Benammar, C.H.; Baghdad, C.H.; Visioli, F. Argan oil reduces, in rats, the high fat diet-induced metabolic effects of obesity. Nutr. Metab. Cardiovasc. Dis. NMCD 2015, 25, 382-387. [CrossRef]

56. Rizzatti, V.; Boschi, F.; Pedrotti, M.; Zoico, E.; Sbarbati, A.; Zamboni, M. Lipid droplets characterization in adipocyte differentiated 3T3-L1 cells: Size and optical density distribution. Eur. J. Histochem. EJH 2013, 57, e24. [CrossRef]

57. Lago, F.; Gomez, R.; Gomez-Reino, J.J.; Dieguez, C.; Gualillo, O. Adipokines as novel modulators of lipid metabolism. Trends Biochem. Sci. 2009, 34, 500-510. [CrossRef]

(C) 2019 by the authors. Licensee MDPI, Basel, Switzerland. This article is an open access article distributed under the terms and conditions of the Creative Commons Attribution (CC BY) license (http://creativecommons.org/licenses/by/4.0/). 